\title{
A VEZ E A VOZ: A ESCUTA NA POESIA DOS ANOS 1970*
}

Lucius Provase**

(iD) http://orcid.org/0000-0003-2030-7299

Como citar este artigo: PROVASE, L. A vez e a voz: a escuta na poesia dos anos 1970 . Todas as Letras - Revista de Lingua e Literatura, São Paulo, v. 22, n. 3, p. 1-13, set./dez. 2020. DOI 10.5935/1980-6914/eLETLT2011883

Submissão: outubro de 2018. Aceite: julho de 2020.

Resumo: O propósito do artigo é partir de uma leitura sobre a voz em certa crítica literária brasileira, relendo uma tradição que estabelece relação direta entre voz e vez, ou seja, quem fala é quem tem o poder, para discutir a poesia marginal. Essa tradição estabelece que um dos problemas da literatura brasileira seria de ceder a vez, e a voz, tornando-se, por meio dessa cessão, verdadeiramente democrática. No entanto, como proponho, a poesia marginal coloca o problema em outra perspectiva ao trazer para o cenário o problema da escuta.

Palavras-chave: Voz. Poesia brasileira. Historicidade. Enunciação. Lastro discursivo.

A Alexandre Nodari 


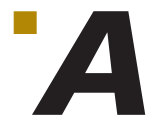

discussão sobre a voz é uma discussão sobre historicidade. Compreendendo "voz" em seu sentido corrente, no qual se aproxima da ideia de fala, ligando o termo a um corpo ("voz" em oposição a "leitura", por exemplo), ou compreendendo "voz" como um espaço discursivo que pode ser ocupado por diversas instâncias sociais (daí a "voz do outro" ou "a voz das ruas") é possivel perceber que a voz, nas obras literárias, tem sido abordada como um problema de fala, ou melhor, de quem fala, de representação, enfim. Junto a isso estão conceitos que, como tentaremos mostrar, não parecem ser mais operacionais para a poesia atual. O exemplo mais gritante dessa falta de função é o "eu" lírico. Além disso, essa postura diante da voz está relacionada a uma visão sobre a História, mais ainda, sobre as relações entre Literatura e História: no progresso histórico, o avanço viria quando todos pudessem falar; a literatura apenas ilustraria essa evolução democrática. Importante lembrar, contudo, que vivemos, hoje, em uma era em que todos podem falar, sem que haja, ao menos de fato, já que há de direito, um espaço discursivo no qual possamos ser ouvidos. Dito de outra forma, hoje todos falam, mas ninguém escuta ${ }^{1}$.

O artigo que segue procurará mostrar, a partir de um confronto com o cenário descrito, de que forma a voz pode ser vista como um problema de escuta. Dito de outra forma, por meio de jogos enunciativos, é possivel problematizar a questão de quem fala, para transformá-la menos em um embate entre excluídos e pertencentes e fazê-la uma instância de problematização dos espaços discursivos de legitimação. Dito de outro modo, tão importante quanto quem fala e como se fala é quem escuta e, mais ainda, como se escuta.

\section{De guem é a vez? Como a voz se torna fala}

Compreender a questão do outro ${ }^{2}$ na literatura brasileira passa, primeiro, por compreender o porquê da questão de o outro ser um elemento relevante na literatura brasileira, mais especificamente, o porquê de a questão da voz ser uma questão relevante. Sabemos que não há questionamentos naturais nas ciências literárias. Toda pergunta surge de um recorte que pode ser influenciado, de forma mais ou menos evidente, por questões ideológicas, posicionamentos políticos, entre outros elementos que poderiamos considerar "não literários".

Desde os primeiros livros sobre a formação do $\mathrm{Brasil}^{3}$, fica claro que a pergunta mais importante a ser respondida é como se deu, se é que se deu, a passagem do Brasil Colônia para o Brasil República e suas repercussões nesse processo. Dito de outro modo: a preocupação é com os processos que fizeram que nosso país se tornasse moderno, ainda que, com a nomenclatura que tendeu a se cristalizar, fosse uma modernização conservadora. O trânsito interdis-

\footnotetext{
Há espaços como o Cooperifa, a Poesia Maloquerista ou mesmo a internet, onde muitas vozes podem falar. No entanto, pesquisas como a da professora Regina Dalcastagné (2012) mostram quanto é ilusória essa percepção de que atingimos uma democracia da voz, já que essas vozes circulam por espaços sem legitimação do sistema literário. Ou seja, apesar de criarem seus próprios sistemas de legitimidade, elas não circulam no espaço que determina, de fato, os valores no campo literário. Essas vozes, nessas condições, são ouvidas?

2 O termo "outro" é pouco esclarecedor e carregado de sentido. Dizer que alguém é o "outro" é despotencializá-lo, colocá-lo em uma posição de clichês. Roberto Schwarz, por exemplo, utiliza o termo "pobre". No entanto, poderíamos pensar em "minorias", "excluídos", "oprimidos", "desempoderados" e tantos outros termos, cada um com sua potência política, ética e estética. Por isso, correndo o risco, optamos por utilizar como termo guarda-chuva, agrupando a diversidade de perspectivas que buscamos trabalhar aqui, ainda que mais centrados nas leituras de Roberto Schwarz, o "outro".

3 Clássicos como Formação econômica do Brasil (1959), de Celso Furtado, Formação do Brasil contemporâneo (1942), de Caio Prado Jr., Os donos do poder (1958), de Raymundo Faoro, Raízes do Brasil (1936), de Sérgio Buarque de Hollanda, Casa-Grande \& Senzala (1933), de Gilberto Freyre, entre muitos outros, como o próprio Formação da Literatura Brasileira (1959), de Antonio Candido.
} 
ciplinar comum aos primeiros autores fez que essa cristalização assumisse um papel paradigmático dentro das ciências humanas como um todo e nos estudos de literatura brasileira em particular.

O ponto central da ideia de modernização conservadora, em sua origem tal qual elaborado por Barrington Moore Jr. (1966) em estudo sobre o desenvolvimento capitalista na Alemanha e no Japão, é de que houve, nesses países, um pacto político entre a burguesia e os produtores agrícolas condicionando o processo de industrialização, diferindo de países como França, Estados Unidos e Inglaterra, nos quais a mudança de sistemas econômicos ocorreu devido a uma revolução, ou melhor, a uma ruptura entre a burguesia e o ancien regime. $\mathrm{O}$ termo foi adaptado à realidade brasileira, talvez sem a devida mediação históri$\mathrm{ca}^{4}$; segundo alguns dos nossos já mencionados estudiosos da formação, o que tivemos aqui foi um pacto entre a elite agrária, oriunda da economia colonial, e a burguesia nascente, que fez que nossa elite econômica nunca fosse totalmente autônoma, resultando em um sistema dependente dos países centrais, com estrutura precária e autocrático. Embora essa leitura tenha pautado boa parte da esquerda dos anos 1960 e sirva de pressuposto para estudos literários até os dias de hoje, ela não foi hegemônica. Francisco de Oliveira (2001) critica o que ele chama de razão dualista e aponta que o sistema brasileiro é mais complexo do que a divisão entre "modernidade" e "atraso", divisão essa associada a um modelo cepalino ${ }^{5}$ de leitura, que não deixava ver algo que Oliveira considerava importante: nessa associação entre atraso e progresso estava a própria modernização brasileira e, talvez, a chave para uma possivel revolução.

Segundo Oliveira (2001), contrariando as vertentes dominantes então utilizadas para explicar o Brasil, não haveria atraso ou subdesenvolvimento a ser superado, já que aquela era a nossa condição moderna, era aquele o nosso capitalismo. Mais: a superação não seria desejada, já que em nosso subdesenvolvimento estaria a chave para uma mudança radical. Impossível não ver aí pontos de diálogos com Oswald de Andrade, com sua poesia Pau-Brasil, e um ensaio famoso de nosso grande crítico literário, Dialética da malandragem, de Antonio Candido $^{6}$. Por que não dizer que o ensaio de André Singer sobre o lulismo também carrega um pouco dessa visão, posto que não vê no carisma de Lula apenas uma personalidade autocrática, um populista ao modo de tantos outros; vê uma possibilidade de mudança real no panorama político, ao apontar que, dessa vez, o pacto classista que impera no Brasil conseguiu incluir as classes mais baixas. Impossivel não ver também que não foi essa a leitura, que a princípio enxerga na suposta peculiaridade brasileira um ponto positivo, a propagada no campo das letras ${ }^{7}$.

4 É preciso, contudo, fazer jus a opus magnum de Florestan Fernandes, A revolução burguesa no Brasil, que busca, justamente, fazer essa mediação. Para os fins deste artigo, no entanto, sem desconsiderar o profundo debate que o termo "modernização conservadora" gera no seio da sociologia e da historiografia, a conclusão a que chega o sociólogo não chega a mudar o ponto de partida: o que ele aponta como a revolução burguesa no Brasil não teve a capacidade de criar um capitalismo independente e uma democracia consolidada.

5 Os "cepalinos" eram os pesquisadores ligados à Comissão Econômica para a América Latina e o Caribe (Cepal), órgão ligado à ONU e que nos anos 1960 foi bastante importante na avaliação da economia brasileira. Teve em Celso Furtado um de seus membros mais atuantes.

6 Infelizmente não poderemos desenvolver, nem é esse o objetivo do trabalho, uma reflexão sobre como Roberto Schwarz se apropria do texto de Candido e do texto de Oliveira em dois ensaios famosos, respectivamente, "Pressupostos, salvo engano, de Dialética da Malandragem" e "Prefácio com perguntas". Neles, com a habilidade ensaística que lhe é habitual, Schwarz acaba por aproximar os textos analisados de uma perspectiva mais cepalina. Aliás, esse é outro ponto muito interessante: em diversos momentos a perspectiva schwarziana se aproxima da perspectiva cepalina.

7 Roberto Schwarz e a leitura que ele faz desse processo desconjuntado da economia brasileira e seu processo de modernização, a partir de Oswald primeiro e depois da Tropicália, é a referência mais famosa, mas não única, no mundo das letras. 
A modernização conservadora, que amarrou boa parte do pensamento mais à esquerda no Brasil desde os anos 1960, casava com o ciclo de grandes interpretações realizado na primeira metade do século, o qual via no passado colonial a origem das principais mazelas brasileiras: o homem cordial de Sérgio Buarque; a indistinção entre público e privado que Caio Prado levanta, assim como Raymundo Faoro; a socialização das perdas de Celso Furtado. Por esse motivo, foi a interpretação que se tornou hegemônica dentre as letras: casava com leituras das mais variadas orientações sobre o processo capitalista no Brasil e servia como chave de leitura, ainda que velada e um tanto anacrônica, para aquele que se tornou, nas mãos de Roberto Schwarz, o paradigma da leitura sobre o Brasil na literatura: Machado de Assis.

\section{Da modernização CONSERVAdora PARA O PROBlema da VOZ - MACHAdo DE Assis E O PARAdigma CRÍtico}

Talvez tenha sido exatamente Roberto Schwarz o responsável por propagar entre a crítica literária, embora o tenha feito como pressuposto não mencionado, a ideia da modernização conservadora. Nesse viés, a boa literatura era aquela que conseguia captar o desencontro entre progresso e atraso, colonização e modernidade, tendo como modelo e paradigma Machado de Assis ${ }^{8}$. A riqueza de Machado estaria na composição dos personagens, retratando não apenas a elite ou os escravos, mas uma multidão de terceiros, os chamados "homens livres", que ajudariam a compor um painel mais exato das idiossincrasias daquela sociedade. Essa é a origem do "outro" na literatura brasileira e aí estaria a sua importância9: é o outro a medida para que sejam construídas leituras que consigam dar conta da complexidade na qual está inscrita a sociedade brasileira com sua modernização conservadora. Na posição do homem livre, resumindo o argumento central de Schwarz em seus livros que tratam de Machado, o primeiro "outro" da literatura brasileira, ficariam evidentes os descompassos entre o atraso e o progresso, caso de personagens como Dona Plácida, Eugênia e Prudêncio, o escravo liberto, cujas posições sociais os obrigam a transitar entre as camadas da elite e dos escravos, já que não são nem um nem outro.

É o personagem pobre, esse "outro", que traria a possibilidade estética de apreciação dos problemas trazidos pela modernização conservadora, suas contradições. Na voz de Schwarz (1999, p. 225):

Nós todos sabemos, mas costumamos esquecer, que o caráter irreal e o deslocamento da modernidade no Brasil não decorrem da incultura das elites, mas da situação apartada e da falta de direito em que vivem os pobres. Esta é a chave de quase todos os problemas politicos e estéticos do pais. [...] Quem diria que um jogo tão britânico e requintado como o andamento das Memórias Póstumas está ligado às discricionariedades de uma sociedade escravista e clientelista? Pois está.

8 O famoso ensaio "Ideias fora do lugar", publicado no livro Ao vencedor as batatas (2001), apresenta o que poderíamos chamar de aspecto estético da modernização conservadora. Segundo o autor, haveria no Brasil ideias europeias, postas e repostas, "em sentido impróprio". Haveria um paradoxo, único e tipicamente brasileiro, que poderia ser resumido no fato de que as ideias aqui não encontravam paralelo nas práticas políticas, sendo a defesa o liberalismo, sem um ataque à escravidão, um dos principais exemplos utilizados pelo crítico.

9 A importância do outro na literatura brasileira não pode ser medida em buscas por grupos de pesquisa na plataforma Lattes ou por palavras-chave. A importância é visível no impacto do texto de Roberto Schwarz, na permanência de uma leitura crítica que tem em sua essência estética uma visão de classe que está fortemente sustentada no pressuposto da chamada modernização conservadora. 
Não é forçoso extrair daí que era a voz o que estava em jogo, ou melhor, a possibilidade de, já que ela aparecia mediada, não era o pobre quem falava, mas alguém que falava por ele. Esse procedimento não diminuía o impacto; pelo contrário, como já apontamos, em Machado, ainda que o escritor não fosse propriamente marginalizado, pobre ou malandro, a caracterização bem feita, ou seja, tensionando essa posição incômoda do pobre, seria suficiente. Ainda em Schwarz (1990, grifo nosso), pincemos uma outra citação:

Nos anos 70, quando escrevia os seus quatro romances fracos, quase privados de atmosfera contemporânea, Machado já era forte nas piruetas petulantes $e$ cosmopolitas do folhetim semanal. O que faltava, para completar a configuração artística da maturidade, não era portanto o procedimento narrativo. A reviravolta pendente, que permitiria incorporar à elaboração romanesca uma técnica disponivel e comum a muitos, era de ordem ideológica.

É preciso primeiro compreender qual o conceito de voz que está embutido nessa leitura, e que influenciou diversas gerações de críticos na relação com a escuta na literatura; vamos direto ao ponto importante: a voz aqui ainda está no nivel da referencialidade, da representação. Não se trata apenas de "mostrar a realidade" (para ficarmos com uma definição corrente de referencialidade e representação que, na verdade, nunca encontrou eco nos estudos literários que trabalharam essa questão mais a fundo); o problema de representação passa por uma mediação precisa e pontual do narrador. Por isso, para ser contemporâneo, não era um elemento estético, antes ético que faltava aos primeiros romances de Machado. Já havia muito do tipo de narrador, mas era a voz do outro que, mediada pelo narrador, teria espaço. Não à toa, muitos estudos sobre Machado, inclusive os de Schwarz, têm no narrador o elemento estético central. O modo como Machado cria posições enunciativas que permitam ao narrador representar criticamente a voz do "pobre", ainda que ela não esteja lá de fato, é o que explicaria, a partir dessa perspectiva, e ao menos em parte, sua grandeza.

Apesar desse jogo enunciativo complexo, que envolve algum grau de escuta, ao analisarmos Machado dessa perspectiva, ainda estamos, para entrarmos na nomenclatura de Jean-Luc Nancy (2002, p. 19, tradução nossa) em seu À l'ecoute, no campo do entendre e não do écouter:

Se ouvir é compreender o sentido (seja em sentido figurado, seja o sentido propriamente dito: ouvir uma sereia, um pássaro ou um tambor é, a cada vez, compreender ao menos o esboço de uma situação, um contexto, ou mesmo um texto), escutar é tender a um sentido possível e, por consequência, não imediatamente acessivel $^{10}$.

Ou seja, estamos no plano da construção de sentido, da semantização, da interpretação. Estamos na dialética entre um "eu" e um "outro", facilmente classificáveis e identificáveis, não apenas em sua voz, mas, sobretudo, em sua posição, seja ela geográfica, social ou, até mesmo, ideológica. É possível dizer que a voz, desacompanhada da escuta, não está posta como o/um problema. Atualizando para a linguagem atual da política de protestos no estilo instant mob, é

10 No original: "Si 'entendre', c'est comprendre le sens (soit au sens dit figure, soit au sens dit propre: entendre une sirene, un oiseau ou un tambour, c'est chaque fois déjà comprendre au moins l'ebauche d'une situation, un contexte sinon un texte), écouter, c'est être tendu vers un sens possible, et par consequente non immédiatement accesible". 
como se os "outros", ou pior, como se alguém, em outra posição social, dissesse que os "outros" dizem: Machado me representa! Resumindo, a qualidade, no que concerne à voz, estaria no fato de que a voz burguesa não consegue esconder a voz do outro.

O problema que decorre dessa postura fica mais evidente quando se trata de trabalhar com a literatura contemporânea. O romance Cidade de Deus oferece uma posição enunciativa mais complexa: a função autor é ocupada por uma voz de dentro; sendo assim, seria o ponto de vista interno o predominante. O limite mais óbvio seria o simples fato de que, a partir desse ponto de vista, não haveria mais um problema ético-político a ser superado pela literatura, mesmo que as realizações estéticas da obra literária não fossem adiante. Retomemos uma citação de Roberto Schwarz (1999, p. 163, grifo nosso) sobre o romance:

O romance de estréia de Paulo Lins, um catatau de 550 páginas sobre a criminalidade na Cidade de Deus, no Rio de Janeiro, merece ser saudado como um acontecimento. $O$ interesse explosivo do assunto, o tamanho da empresa, a sua dificuldade, o ponto de vista interno e diferente, tudo contribuiu para a aventura artística fora do comum. A literatura no caso foi levada a explorar possibilidades robustas, que pelo visto existem.

Dessa vez era o pobre quem falava e, em diversos niveis, aqui culminava o que havia começado em Machado de Assis. Não pelo ganho estético, mas pelo ganho político e ideológico embutido nessa voz que se levanta, a voz do pobre. A visão de Schwarz, ainda que apresentada aqui em forma resumida e por isso com o risco de ser simplificada em demasia, deixa passar algumas complexidades nas relações sociais brasileiras, sobretudo no que concerne à crescente classe média brasileira. Isso porque ainda vê no clarear daquilo que a ideologia esconde o caminho da superação. É preciso questionar, porém, se em tempos de aparelhamento cada vez mais evidente das instituições públicas, caso claro no escândalo de Carlinhos Cachoeira, ou na multiplicidade de vozes que falam nos recentes protestos que ocuparam as ruas das cidades brasileiras, desnublar a ideologia mantém-se como a tarefa principal da crítica, mais importante do que compreender os processos de construção dos procedimentos citados.

Ainda quanto à perspectiva enunciativa do romance de Paulo Lins, a narrativa quase cinematográfica, que utiliza a terceira pessoa sem abrir mão de confundir a ação com a própria narração, é em tudo diferente de Machado. Ainda com Schwarz (1999, p. 167):

[...] colado à ação o ponto de vista narrativo lhe capta as alternativas próximas, a lógica e os impasses. O imediatismo do recorte reproduz a pressão do perigo e da necessidade a que os personagens estão submetidos. Daí uma espécie de realidade irrecorrível, uma objetividade absurda, decorrência do acossamento que deixa o juízo moral no chão.

Não é apenas a questão de "falar de dentro"; essa perspectiva traz consigo uma "objetividade absurda", uma tomada cinematográfica. Ou seja, ao trazer aquele que viveu o problema como narrador, não há mais distância relevante entre o que se narra e o que se vive; arte e vida borram suas fronteiras gerando a objetividade que só pode existir quando quem fala é quem de fato vive. É como se o projeto das vanguardas artísticas dos anos 1960 ganhasse vida novamente, e anacronicamente. 
Embora só tenhamos oferecido o exemplo ${ }^{11}$ de Schwarz, não tardou para que outros críticos percebessem o problema embutido na linha de raciocínio de Schwarz e como, a partir daí, havia um claro limite para chegarmos à literatura contemporânea. Dentre esses críticos, João Cézar de Castro Rocha $(1998,2004)$ foi quem mais diretamente (e declaradamente) "comprou a briga" de repensar o projeto de leitura do Brasil sem, contudo, jogar o bebê com a água, ou seja, propondo outras leituras a partir de lugares frequentados pela crítica identificada ao conceito de "formação".

Essa revisão, se podemos chamar assim, fica mais evidente com o conceito de "dialética da marginalidade", óbvio diálogo com Antonio Candido, mas que também aparece em livros e artigos do autor ${ }^{12}$. Escolhemos debater, por se alinhar ao estudo da voz que procuramos desenvolver, os textos em que o autor escolhe como ponto de debate a dialética da marginalidade. Nesses textos é a referencialidade, ou representação, para pensarmos em um termo da ciência política, que aparece como centro da discussão. Há um importante deslocamento do problema, mas não há uma mudança tão grande de perspectiva: embora aponte diversas vezes que a questão do valor de obras como Cidade de Deus não está na suposta ausência de mediação (o que no fundo é uma ficção, como mostra Rocha) ou no material bruto que parecem oferecer, ao valorizar o fato de que o que está em jogo é a construção da imagem pelos próprios marginalizados, não continuamos, no fundo, a trabalhar o problema da voz? Reitero: obviamente, importa quem fala. É um avanço que tenhamos literatura produzida por mulheres, negros, pobres, enfim, que a literatura reflita de fato, por meio de seus autores, a diversidade social sob o risco de tornar-se, cada vez mais, inócua. No entanto, problematizar a voz não seria uma questão importante para esses que falam pela primeira vez? Tão importante quanto "falar" não seria o "quem escuta"?

Diante desse posicionamento cada vez mais direto e pouco abstrato com a voz, proliferam os estudos sobre memória, relato, biografia e autobiografia. Gêneros que incorporam a fala como elemento fundador e central. Esse tipo de abordagem não trabalha nas bordas; faz do tempo e da história, assim como da voz, algo linear e objetivo. O processo de escuta, voltando a Nancy (2002), nos permite pensar em outras formas de trabalhar com a voz, pensá-la como aquilo que ressoa, que não é apenas o fenômeno acústico, mas uma espécie de permanência:

Estar na escuta é sempre estar no limite, ou em um sentido de limite ou de extremidade, como se o som não fosse precisamente nada além desse limite, essa zona ou essa margem - ao menos o som que escutamos musicalmente, quer

11 Há uma grande quantidade de críticos que adotam perspectiva semelhante à de Roberto Schwarz, qual seja: a "voz" na construção literária está a serviço da representação de uma nação. Dito de outra forma, quem fala é importante na medida em que traz os conflitos esperados por uma posição de classe ou ao menos permite, por meio dessa voz, evidenciar os conflitos de classe presentes em determinado estrato social. Assim, a poesia marginal é de pouco interesse por não problematizar os conflitos, apenas celebrá-los, se seguirmos algumas leituras predominantes sobre a poesia dos anos 1970; a poesia concreta, por sua vez, não seria nacional o suficiente e em sua ânsia por ser universal, torna-se provinciana, diria outra vertente consolidada de leitura; voltando à visão de Schwarz, o mesmo pode ser dito de Oswald de Andrade, por exemplo. A leitura que o crítico faz do modernismo de primeira hora, aliás, não é nada positiva, justamente por enxergar naqueles autores uma celebração do que seria o atraso brasileiro, algo que pode ser visto nos ensaios "A carroça, o bonde e o poeta modernista" e em "O psicologismo em Mário de Andrade".

12 A referência a Sérgio Buarque de Holanda no livro Literatura e cordialidade, os artigos e livros sobre Machado de Assis, sempre um ponto importante de revisão de paradigmas no campo literário brasileiro, além de artigos sobre escritores e pensadores ligados à formação - Gilberto Freyre, Euclides da Cunha, entre outros - são todas evidências de que há um desejo de dialogar com o que há de constituído no campo literário, sem abrir mão de trabalhar com o que foi produzido mais contemporaneamente. 
dizer, coletado e escrutinado ele mesmo; não, entretanto, como fenômeno acústico (ou não apenas), mas como sentido ressonante, sentido no qual o significado é concebido para ser encontrado na ressonância e ser encontrado apenas nesta (NANCY, 2002, p. 21, tradução nossa) ${ }^{13}$.

É como dizer que o trabalho com a voz que foca unicamente a possibilidade de fala fosse um trabalho com o enunciado, com o dito, deixando de lado o dizer, a enunciação, em uma aproximação um pouco grosseira. Pensar a voz como um problema de escuta nos coloca mais próximos do movimento que ocorre em qualquer produção textual.

Isso fica claro, por exemplo, nas leituras que Schwarz faz de Francisco Alvim, autor contemporâneo cujos poemas, segundo o crítico, trariam a voz do outro, como no poema a seguir:

\section{MAS}

É limpinha

A chave crítica estaria, nesse caso, em recortes enunciativos que deslocam, e assim evidenciam, o que o texto, contextualizado, esconderia: o ranço de preconceito e a marginalização que ocorrem em nossa sociedade. Na voz do autor:

O conteúdo do poema naturalmente é tudo o que ele cala e que terá precedido a adversativa do título: a enciclopédia das objeções que os proprietários fazem aos sem-propriedade, obrigados a trabalhar para eles, à qual no caso só escapa a virtude menor que tem uma mocinha de não ser muito suja. A expressão não perde nada ao passar da sala de estar para a zona do meretrício, como bem observou um amigo (SCHWARZ, 2002).

Ainda segundo o crítico, a força de Alvim estaria na

[...] generosidade não-burguesa do impulso que leva o artista culto a buscar o autoconhecimento e a expressão em palavras e situações alheias, do outro lado da divisória, superadas as barreiras que separam o aprovado do reprovado ou desprezado. E, de fato, a figura artística de Chico respira uma atmosfera de humanidade que é excepcional e deriva dai. Entretanto, as divisões sociais que opõem os patrícios nem por isso deixam de existir, e a simpatia atenta do poeta não só não as apaga, como as salienta e oferece à contemplação (SCHWARZ, 2002).

Ou seja, ainda que a voz não seja a voz do pobre, sua humanidade mostraria aquilo que a voz burguesa procura esconder. A disposição à escuta é apontada como um valor.

\section{Se todos FAlAM, gUEM ESCUTA? UM PARAdigma PARA A POESIA DA DÉCADA DE 1970}

Cacaso, um dos grandes poetas da geração dos anos 1970, deixou registrado em um artigo inacabado sua visão sobre Francisco Alvim: o poeta dos outros. O

\footnotetext{
13 No original: "Être à l'écoute, c'est toujours être en bordure, ou dans un sens de borde ou d'extrémité, et comme si le son n'était précisément rien d'autre que ce borde, cette frange ou cette marge-du moins le son musicalement écouté, c'est-à-dire recueilli et scruté lui-même, non pas cependant comme phénomène acoustique (ou pas seulement) mais comme sens résonant, sens dont le sensé est censé se trouver dans la résonance, et ne se trouver qu'en elle".
} 
título é ainda mais claro: "Ceder a vez, ceder a voz". Para o diálogo que tentamos construir aqui, o problema que Cacaso enfrenta talvez possa ser levemente deslocado: "Ceder a vez, ceder a escuta". De qualquer forma, o problema colocado parece coincidir com a questão que Schwarz encontra no mesmo poeta, a saber, Alvim seria aquele que tem a sensibilidade da escuta e, em sua escrita, traria como problema a questão de quem fala e como fala. Ou seja, o que Alvim faria é mostra de que, ao menos na literatura, a voz não coincide com a representação (ou com a representatividade). Lemos, em seus poemas, frases recortadas de situações e cenários que, à primeira vista, poderiam ser colocadas lado a lado com outras representações clássicas da classe dominante ou de um sujeito lírico tradicional, que também se identifica com uma classe dominante. No entanto, o que encontramos é muito distinto dessa simples questão de representatividade. Vejamos dois poemas: "Almoço", do livro Passatempo, de 1974, e o já mencionado "Mas", do livro Elefante, de 2000.

\section{Almoço}

Sim senhor doutor, o que vai ser?

Um filé mignon, um filezinho, com salada de batatas

Não: salada de tomates

E o que vai beber o meu patrão?

Uma caxambu

É possivel perceber que quem fala, em ambos os textos, não é alguém excluído. No entanto, essa voz não se coloca como representação, ao menos não no sentido político tradicional, e sim como a posição de tensão daquele que fala. Tanto a situação descrita no poema "Almoço" quanto a frase, exposta de forma crua, no poema "Mas", não servem como reafirmação de uma postura ideológica, tampouco como desvelamento ou denúncia. Dito de outra forma, o tensionamento que é provocado por esse deslocamento da situação de enunciação não parece ter como objetivo a simples revelação de um comportamento ou a representação crua de determinada camada social. Alvim, como outros poetas da mesma geração, adota o deslocamento da enunciação como ferramenta de indeterminação. Em vez de um juízo pronto, essa operação propõe um constante reconstruir de sentidos, que gera instabilidade na posição de quem fala e de quem escuta. Se essa instabilidade é, de certa forma, inerente ao fazer poético, já que o leitor tanto pode se colocar na posição de sujeito da enunciação quanto de interlocutor desta, no caso da poesia marginal, o fato de a própria poesia não se decidir entre falar e ouvir produz uma distorção, uma outra historicidade. O poema passa a ter sua própria ontologia, ainda que variável, já que ele não é mais uma construção a priori ${ }^{14}$, um dado pronto oferecido ao leitor, mas constrói-se durante o próprio ato de leitura. Se em um poema romântico, "Canção do exílio", por exemplo, o leitor poderia ou não se identificar com a posição dada do sujeito da enunciação, no caso de diversos poemas marginais, o leitor deve responder à pergunta: quem é o sujeito dessa enunciação? Assim, ainda que a

14 O contexto no qual isso se torna possível, ou seja, que o leitor se aproxime do texto sem uma definição prévia do que é aquele objeto, depende de uma crescente perda do lastro discursivo. Discute-se detidamente como se deu essa perda em minha tese "Lastro, rastro e historicidades distorcidas: uma leitura dos anos 70 a partir de Galáxias" (PROVASE, 2016), mas, em resumo, trata-se do distanciamento insustentável entre, nos termos do historiador Reinhardt Koselleck (2006), espaço de experiência e horizonte de expectativa, criando um presente absoluto. Tal presente absoluto dificulta a criação de um sensível partilhável, tornando a criação de um lastro discursivo, uma série de elementos comuns e compartilhados entre grupos, inviável, até mesmo impossível. 
confusão entre voz e escuta seja constituinte da poesia, em muitos casos tal indistinção não é um ponto de partida do ato de leitura.

No exemplo mencionado de Gonçalves Dias, o leitor sabe que aquilo é um poema, sabe como ele, o poema, opera por meio de suas rimas, sua métrica. Esse conhecimento comum indica um caminho possivel. Mesmo nos poemas modernos, de Mário, Bandeira, Oswald, ainda havia o apoio na certeza do que era um poema para a construção do texto. A possibilidade de chocar com um poema como "Os sapos" só existe quando a constituição do poema é um dado compartilhado. Além disso, mesmo nos poemas modernos, o jogo com a enunciação ainda é incipiente, quando não inexistente. Um poema como "Almoço" depende desse deslocamento e da instabilidade que dele é gerada para produzir algum sentido, se compararmos com outros textos como "Poema tirado de uma notícia de jornal", de Manuel Bandeira, ou ainda a série "Pero Vaz de Caminha", do Poesia Pau-Brasil, de Oswald de Andrade. Nesses textos, em que, respectivamente, um acontecimento banal é transformado em poesia e trechos da Carta de Caminha são recortados e transformados em poesia, é dito e informado ao leitor a referência, de onde saíram aqueles versos e palavras, como aquilo poderia se constituir em um poema. Além disso, em ambos os casos, há uma tentativa de poetizar, seja pelo ritmo, no caso de Bandeira, seja pela inserção de títulos, no caso de Oswald. O leitor não precisa decidir se aquele texto é ou não um poema. Esse mínimo múltiplo comum discursivo é fundamental para a operação de sentido que os textos dos poetas modernistas operam. No texto dos anos 1970, porém, essa instabilidade atinge a escrita como fundamento. A relação entre arte e vida, mote de um poeta e pesquisador como Cacaso e, por extensão, de toda uma geração, aponta para essa tensão ${ }^{15}$. A pergunta "o que é um poema?" funciona como fundamento.

Essa é, justamente, a pergunta que fica quando lemos não apenas os poemas de Francisco Alvim, mas também textos de Ana Cristina César ou Cacaso, para ficar com dois outros exemplos clássicos da poesia dos anos 1970. Ambos produzem a partir do mesmo procedimento de deslocar as situações enunciativas, produzindo uma instabilidade de sentido que faz que o poema exija uma implicação direta do leitor em sua construção e a decisão fundamental de como aquele texto será recebido. Outros poetas, como Torquato, Waly e Guilherme Mandaro, também se utilizam do mesmo instrumento na produção de seus textos. Essa é, aliás, uma característica comum e marcante dessa geração, e que ecoa na produção contemporânea. Aquilo que foi lido, certa vez ${ }^{16}$, como diluição dos procedimentos utilizados pelos poetas modernistas.

Em Ana C., por exemplo, o que se convencionou chamar de ficção do "eu" poderia ser lido nessa mesma chave. As encenações são deslocamentos da situação de enunciação que provocam essa instabilidade do próprio sujeito da enunciação. Ana Cristina César também trabalha com a posição da escuta, como aquela que colhe indiscriminadamente o que ouve em sua experiência. A diferença fundamental de seus textos para o texto de Alvim é a presença de gêneros intimistas em sua poesia; a carta e o diário chamam a atenção para o sujeito da

15 Em minha dissertação de mestrado (PROVASE, 2010), apontei de que forma os procedimentos poéticos aqui mencionados levavam, em Cacaso, a uma instabilidade do lugar do poema. Roberto Zular, no texto "Sereia de papel (algumas anotações sobre a escrita e a voz em Ana Cristina César)", mostra como também em Ana C. esses mesmos procedimentos levam a um questionamento da escrita como um a priori, apontando para um comum entre outros poetas da década de 1970.

16 A referência mais conhecida dessa chave de leitura é o texto de Simon e Dantas (1985), "Poesia ruim, sociedade pior". 
enunciação. Em Ana C., já no livro Cenas de abril, de 1979, a série com datas, que remete ao gênero diário, é um exemplo sólido dessa situação. Convidado a invadir a intimidade do sujeito da enunciação, o leitor, em um primeiro momento, é mero ouvinte, um quase voyeur. No entanto, a instabilidade gerada pela posição da voz faz do ato da escrita algo também instável ${ }^{17}$. Analisando poema do mesmo livro, "Nada, esta espuma", Roberto Zular (2015, p. 96) comenta a referência a Mallarmé presente no texto e chega à seguinte conclusão:

[...] Nomear o inominado aqui é tentar cravar pelo enunciado a força da enunciação. De um modo aparentemente insuspeitado, a poesia dos anos 70 tenta algo semelhante, mas, digamos assim, pelo lado da vida, tentando encontrar aquele ponto em que a vida toca a poesia (o famoso "eu não te escrevo/ eu te/vivo" de Cacaso).

Ainda sobre o poema, Zular (2015, p. 96) destaca a maneira como há "um jogo que ficcionaliza, além dos atos da escrita, as situações de enunciação", produzindo uma "ecolalia enunciativa tanto de atos de fala quanto de escrita". Tal movimento enunciativo criado pelo poema "se dirige a um lugar de trânsito que atravessa as vozes para colocá-las no limiar do que ainda não está lá, mas para o qual o poema aponta, como veremos, na sua formulação dêitica e metonímica" (ZULAR, 2015, p. 97). O sujeito da enunciação deste poema produz uma primeira pessoa que não é "nem identidade (lastro), nem falta (pura negatividade - como muitas leituras de Mallarmé) -, mas um lugar de articulação, aquilo que faz girar as possibilidades [...] que produz um outro lugar na relação corpo e linguagem [...]" (ZULAR, 2015, p. 97).

A ontologia, variável, do poema torna-se essencial para constituição da historicidade do texto. Não se trata apenas de pensar em autor-leitor-circulação como o conjunto que produz um contexto, mas nos diversos contextos que se combinam, sem se suprimir, para produzir a historicidade distorcida que ali opera. A voz não pode mais ser apenas uma questão de representação, sendo, também, uma ontologia, ao menos nessa combinação com a escuta. As diferentes perspectivas daí oriundas, o poema como um objeto ontológico, faz que o problema da representação seja deslocado. À ideia de um lugar de fala deve-se somar o lugar de escuta. Importa, tanto quanto quem, de onde e como se fala, quem, de onde e como se escuta. Importa, mais do que a perspectiva, o jogo que a constitui.

Pensar a voz a reboque da ideia de representação, ou de referenciação, como ainda ocorre, acaba por apagar a possibilidade de pensar a escuta, ainda que esta devesse estar atrelada à voz. Quando pensamos a voz como um problema de quem fala apenas, a historicidade aí construída está predeterminada. A voz, que deveria ser uma questão antropológica, de modos de ser, possibilidades de afeto, de ontologias, passa a ser um problema politico, no sentido mais chão de disputas de perspectiva. A poesia produzida nos anos 1970 se constrói na complexidade dessas duas noções, voz e escuta, obrigando que a tomada de posição do leitor leve em conta essa perspectiva antropológica diante da voz e da escuta para que tal complexidade seja assumida.

17 Trabalhei essa questão, presente em Cacaso, em meu mestrado. Parece-me ser algo recorrente nos poetas dos anos 1970. A questão arte e vida faz que o poema, para esses autores e autoras, esteja sempre a um passo de ser experiência vivida. Porém, lá está o poema. O binômio entre arte e vida, no entanto, permanece e invade as posições possíveis de enunciação, fazendo da voz um movimento de composição da historicidade do texto. Daí a ontologia variável. 


\section{VOZ, ESCUTA E PERSPECTIVA}

A proposta que sustenta o presente artigo é que a poesia da década de 1970 quebra o paradigma relacional entre voz e vez, ou seja, coloca o problema da voz numa chave que não é a da representação, mas sim ontológica. Isso quer dizer que interessa, adotada essa perspectiva, compreender qual o mundo que se propõe naquele poema, obrigando a uma historicidade radical e distorcida da linguagem, posto que essa historicidade se constitui no (des)encontro da tríade autor-leitor-obra.

Ao voltarmos à poesia que propõe esse novo paradigma não só deixamos para trás o estigma da poesia associada ao desbunde, mas abrimos uma chave interpretativa que auxilia a compreensão de certa poesia contemporânea ${ }^{18}$, que também adota o procedimento da escuta na construção dos poemas. O interesse em buscar outras chaves de leitura para a poesia produzida a partir dos anos 1970 no Brasil é, mais do que criar filiações ou estabelecer relações, abrir-se para a multiplicidade de respostas estéticas e, portanto, ético-políticas, que foram dadas às intensas mudanças ocorridas desde aquele periodo até as duas primeiras décadas do século XXI.

\section{VOICE AND TURN: THE POETRY OF 1970's}

Abstract: The purpose of this article is to propose a discussion about the use of voice as a concept in a certain Brazilian literary criticism, re-reading a tradition that establishes a direct relationship between voice and power, as a tool to read the so called "marginal poetry". This tradition establishes that one of the problems of Brazilian literature would be who has the right to speak, becoming truly democratic only when they could speak for themselves. However, as I propose, marginal poetry puts the problem in another perspective by bringing the question of listening to this scenario.

Keywords: Voice. Brazilian poetry. Historicity. Utterance. Discursive ballast.

\section{REFERÊNCIAS}

DALCASTAGNÉ, R. Literatura brasileira contemporânea: um território contestado. Vinhedo: Editora Horizonte, 2012.

KOSELLECK, R. Futuro passado: contribuição à semântica dos tempos históricos. Rio de Janeiro: Contraponto: Ed. PUC-Rio, 2006.

MOORE JR., B. Social origins of dictatorship and democracy: lord and peasant in the making of the modern world. Boston, MA: Beacon Press, 1966.

NANCY, J.-L. À l'ecoute. Paris: Galilée, 2002.

OLIVEIRA, F. de. Crítica a razão dualista/O ornitorrinco. São Paulo: Boitempo, 2001.


específico com o deslocamento enunciativo, mas utilizando mídias e linguagens distintas. 
PROVASE, L. Lastro, rastro e historicidades distorcidas: uma leitura dos anos 70 a partir de Galáxias. 2016. Tese (Doutorado em Letras) - Faculdade de Filosofia, Letras e Ciências Humanas, Universidade de São Paulo, São Paulo, 2016.

PROVASE, L. Da experiência de escrever ao ato da escrita: vida e arte na poética de Cacaso. 2010. Tese (Mestrado em Letras) - Universidade de São Paulo, São Paulo, 2010.

ROCHA, J. C. de C. Literatura e cordialidade: o público e o privado na cultura brasileira. Rio de Janeiro: Edeerj, 1998.

ROCHA, J. C. de C. Dialética da marginalidade (Caracterização da cultura brasileira contemporânea). Folha de S.Paulo, Caderno Mais, 29 fev. 2004.

SCHWARZ, R. Sequências brasileira: ensaios. São Paulo: Companhia das Letras, 1999.

SCHWARZ, R. Ao vencedor as batatas. São Paulo: Ed. 34, 2001.

SCHWARZ, R. O país do elefante. Folha de S.Paulo, 10 mar. 2002. Disponivel em: http:/ /www1.folha.uol.com.br/fsp/mais/fs 1003200204.htm. Acesso em: 5 abr. 2007.

SCHWARZ, R. Acumulação literária e nação periférica. Folha de S.Paulo, 23 jun. 1990. Disponivel em: http://almanaque.folha.uol.com.br/machado2.htm. Acesso em: 3 jun. 2006.

SIMON, I. M.; DANTAS, V. Poesia ruim, sociedade pior. Novos estudos Cebrap, São Paulo, n. 12, p. 48-61, jun. 1985.

ZULAR, R. "Sereia de Papel (algumas anotações sobre a escrita e a voz em Ana Cristina César). In: ZULAR, R.; FALEIROS, A.; BOSI, V. (org.). Sereia de papel: visões de Ana Cristina Cesar. 1. ed. Rio de Janeiro: Eduerj, 2015. v. 1, p. 81-103. 